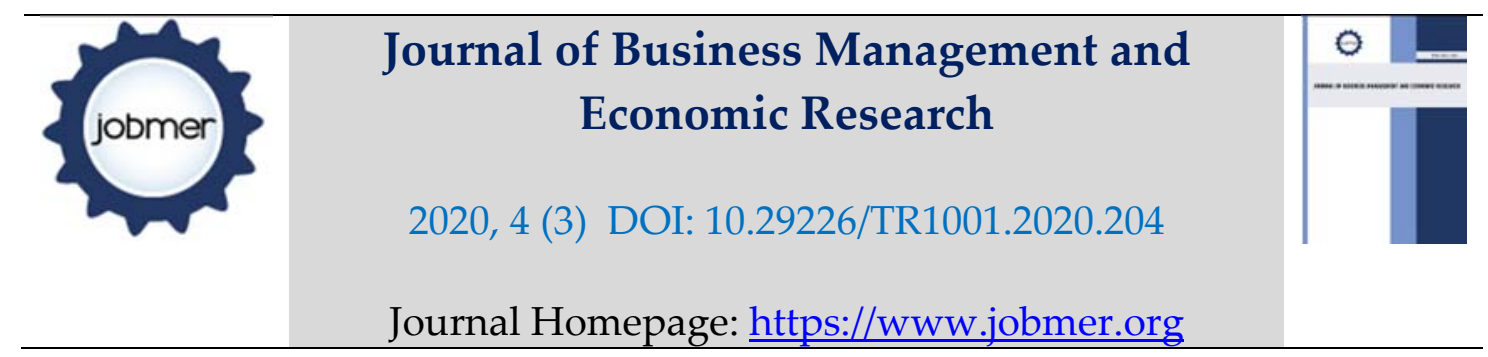

\title{
Effect of Prospecting Bias on Investment Decision Making among Small and Medium Enterprise in Nairobi County
}

\section{Leah Jemutai Barno}

Phd Student, Moi University

jemutaileah@yahoo.com

\section{Joseph Kiprotich Tuwei \\ Senior Lecture, Moi University}

\begin{abstract}
Investment decisions made by Small and Micro enterprises are crucial for economic development. It involves high capital outlay that provides economic benefit to the SMEs. Despite the risky decisions made by both Small and Micro Enterprises, this sector remains the largest employer and a source of revenue to the Kenyan government. Investment decision is an important part of strategic decision-making in every enterprise because new investment projects essentially affect future economic results and the enterprise's prosperity. This study thus sought to determine the effect of prospect bias on investment decisions among small and micro enterprises in Nairobi County. The specific objectives of the study were to: determine the effect of overconfidence, anchoring, prospecting and herding on investment decision making as well as to investigate the moderating effect of financial literacy on the relationship between overconfidence, anchoring, prospecting, herding and investment decisions among Small and Micro Enterprises. The study was premised prospects theory. Positivism paradigm was deployed. The study adopts explanatory research design. The target population were 102,821 firm owners. A sample of 383 respondents was selected using stratified random sampling technique. The findings from regression model showed results revealed that prospect factors had a positive and significant influence on investment decision $(\beta=0.288, \mathrm{p}<0.05)$. Therefore, entrepreneurs should consider carefully before making investment decisions though they should not care too much about the prior loss for their later investment decisions.
\end{abstract}

Keywords: Prospect Bias, Investment Decisions, Small And Micro Enterprises

\section{Suggested Citation:}

Barno, L. J. and Tuwei, J. K. (2020). Effect of Prospecting Bias on Investment Decision Making among Small and Medium Enterprise in Nairobi County. Journal of Business Management and Economic Research (JOBMER), Vol: 4, Issue: 3, 253-266 


\section{Introduction}

Investment decision is the process of making a choice from alternatives which involves capital outlay for future cash flows in long term growth of a business. Most investment decisions are risky thus these decisions involve a high degree of risk. It is a part of strategic decision-making in every enterprise because new investment projects essentially affect future economic results and the enterprise's prosperity. Success of new projects contributes to growth of an enterprise's efficiency. On the other hand, unsuccessfulness can lead not only to a considerable decline in efficiency but also jeopardize its future existence. Thus, Success or unsuccessfulness of projects considerably depends on the quality of the process of preparation, evaluation and selection of these projects (Schwab, 2017).

The relationship between prudent investment decision making capability of a firm's managers and its advantage in analyzing a target investments financial performance is vital. Managers are perceived to have more information than other investors regarding an investment, thus, managers are vital in making prudent investment decision that can lead to better performance of a company in both financial and non-financial parameters (Akintoye \& Olowolaju, 2008). Investment decisions regarding the various forms of capital input have also been positively linked to financial performance; the stochastic outcome of a firm's own investments in aspects such as, physical capital, human capital, research and development expenditure increases firm's production capacity hence boosting its financial performance (Levasseur, 2002). Kengatharan and Kengatharan (2014) alluded that investment decision is influenced by behavioural factor based on a research in Sri Lanka. Market, prospect, heuristics and herding had significant effect with anchoring leading on investment decision, hence, choice of stock made was negatively affected by herding, just like overconfidence. Anchoring positively affected the investment performance. From this finding some behavioural factor contribute positively and others negatively.

Kahneman and Tversky cited in Velumoni (2017) argued in their prospect theory describes prospect as how individuals evaluate losses and gains. Investor value system in prospect theory are regret aversion, mental accounting and loss aversion (Waweru et al cited in Velumoni, 2017). Regret aversion is a cognitive event in investment decision where investors hold onto losing positions too long in order to avoid admitting error and realizing losses. On the other hand, loss 
aversion is the tendency where investors dislike loss more than gain. Mental accounting as aspect of prospect describes tendency to code categorize and evaluate outcome by grouping their assets into any number of non-interchangeable mental accounts. The three component explains who prospect factors.

Small and Micro Enterprises have a significant change the economy through employment, source of revenue, sources of goods and services as well as source of market for local goods. Despite the success stories there are numerous of business who either failed at starting or growth stage. Recently 2019 the fail of the giant business ventures Nakumatt and Uchumi supermarket (Wainaina, 2020) that started as SMEs has rob a lot of jobs to youth. Such fails of enterprises not only affect employee who benefit from salary but creditors from suppliers and loan providers. Investment decision is crucial and wrong decision may lead to a loss in an organization. Most Small and Micro Enterprises (SMEs) have high rate of failure based on investment decisions they make where three out of five businesses fail within the first few months of operation (Kenya National Bureau of Statistics, 2007). SMEs face various challenges when it comes to rational decision making such as limited managerial skills, experiences, challenges in academic ability and sometime personal behavior influence judgement. However numerous paradigm investment decisions can be positively or negatively linked to financial performance or business success depending on whether these decisions are made with or without biasness. Hence there is need to investigate on prospect bias that affects the success of Small and Micro Enterprises. The following hypotheses are tested;

H1: Prospecting has significant effect on investment decision making among SMEs in Nairobi County.

\section{Theoretical and Literature Review}

The prospect theory was proposed by Kahneman and Tversky in 1979 (as cited in Fulfer \& Maille, 2018). The important aspect of prospect theory is an S-shaped value function which is concave (risk averse) in the domain of gains and convex (risk loving) in the domain of losses. Both these points are rated relatively to a reference point. Mental accounting gives a basis for the way decision makers set reference points for the statements that determine gains and losses (Thaler, 2008). The main foundation is that decision makers separate different types of gambles into various accounts 
and then use prospect theory to each account by disregarding possible interactions (Marchand, 2012).

Prospect theory describes how people frame and value a decision involving uncertainty and therefore they look at choices in terms of potential gains or losses in relation to a specific reference point, which is often the purchase price. This theory also outlines the way economic agents put a result or transaction in their mind and influence the utility they receive. Framing and economic theory has been used in a wide range of situations which don't rhyme with standard economic objectivity (Wang, Yang, Li, and Zhang, 2016). Jagullice (2013) opined that the prospect theory adopts a consequentialist approach to choose, suggesting that in making financing decisions people are assumed to be concerned with the likely outcomes of their actions. A key operation in decision making according to prospect theory is the coding of outcomes into gains and losses; this represents one of the most important characteristics of the decision maker: that outcomes are perceived in terms of gains and losses relative to some reference point, which might be the status quo, or the framing of the problem; or the expectations or history of the decision maker.

Prospect theory has been utilized to explain financing decisions. Ljungqvist and Wilhelm (2005) investigated whether prospect theory can explain the behavior of managers in the Initial Public Offering (IPO) and Search Engine Optimization (SEO) market. This theory is relevant to the study since it informs the basis for the independent variables; overconfidence bias, prospect, anchoring and herding. The theory is applied in this study to explain how SMEs financial mangers' behaviors affect the way they make financial decisions in terms of perceived gains and losses. A manager who is regret averse will make financial decisions based on how much gains it would result in and not how much loss it would result in. A conservative manager will make financial decisions based on the loss or gain experienced in the past investments.

\subsection{Empirical Review}

Velumoni (2017) did an analysis of prospect theory on equity investment decision making. The research adopted prospect theory which examined on the mental accounting, loss aversion and regret aversion. It used primary data that were collected from 303 respondents who are equity shares investors. Linear regression, t-test and ANOVA were used as inferential tools. The study 
found no significant difference between behavioural factors and socio demographic variables. Behavioural factors based on prospect theory had significant influence on the investment decision. Duclos (2015) study on psychology of investment behaviour focussed on the biasing financial decision making one graph at a time. The research investigates on the behaviour associated with the way manager develop graphical displays for financial information where they need to project the future trends and make investment decision based on the information. Duclos (2015) considered five investors as an experiment and found that the last trading day of stock provided excessively information that was important to the investor known as end-anchoring. Considerably investors would treat stock closing upward would focus upwards forecasts in the following day likewise to downward focus. Investment asymmetries indicated that stock-price distributions were produced randomly to simulate times and hence market conjuncture is hesitant hence no real upward or downward trend is identified.

A study by Chetankumar and Hiral (2018) showed that investment decision making was significantly influenced by behavioral factors. The study was conducted in South Gujarat region in India. The study was based on testing whether behavioral model which segment the behavioral factor into heuristic theory (representativeness, gamblers fallacy, anchoring, overconfidence and availability), prospect theory (regret aversion, loss aversion and mental accounting), Market factors and herding factors. The current study will focus on anchoring, overconfidence, prospect and herding factors. A similar research by Sochi (2018) investigated on behavioral factors influencing investment decision in Dhaka Stock Exchange based on an empirical study, found significant influence of behavioral biasness on investment decision.

Luu, (2014) conducted a study on behavioral factors influencing the decisions of individual investors at the securities companies in Vietnam. The study assessed the effect of five behavioral factors; herding, market, prospect, overconfidence and anchoring. The study sampled 300 individual investors selected randomly from the investment companies. The questionnaires were used to collect data, from the 300 questionnaires given, 188 were returned duly filled. The data were analysed using descriptive statistics; mean and standard deviations. The current study will be done in Kenya focusing on the four behavioral factors which include herding, prospect, overconfidence and anchoring avoiding market which is not a heuristic behaviour rather than an 
external factor. This study adopts descriptive research design and the use of questionnaires. In Luu (2014) findings indicated a positive influence of behavioral factors on the performance of the organization.

\section{Material and methods}

The study employed explanatory research design in positivist paradigm, this paradigm was selected since the study employed the quantitative data to establish direct and moderating effect of the variables under study. The concept of Positivism is directly associated with the idea of objectivism. This prompt for structured questionnaires and a larger number of sample as compare to its counterpart paradigm. The study used explanatory research design to assess and establish the effect of behavioral factors, financial literacy on SME investment decisions in Nairobi County. A target population of 102,821 registered SMEs within Nairobi County were considered (Nairobi County, Ministry of Trade, 2016). Managers were selected purposively on the grounds that they are in a superior position to comprehend investment decision issues of SMEs and in a position to give the correct data. Based on hyper-geometric distribution formulae, the study used stratified and random sampling technique to select a sample size of 383. Similar studies (Morris, 2014) have adopted the hyper-geometric distribution due to its ability to estimate sample sizes from large populations accurately. The study used questionnaires to collect primary data. The study adopted primary data collected from firms, or entrepreneurs through structured and unstructured questionnaires. Snapshots or cross-section method was used since data extracted only with the collection period. It employed quantitative approach where quantitative techniques were utilized. Data collected were using 5 point Likert scale which was coded to numerical data using ordinal scales.

\subsection{Measurement of Variables}

The 5-point Likert scales, which are rating scales widely used for asking respondents' opinions and attitudes (Fisher, 2010), were utilized to ask the individual investors to evaluate the degrees of their agreement with the impacts of behavioral factors on their investment decision as well as with the statements of investment behavior. The 5 points in the scale are respectively from 1 to 5 : strongly disagree, disagree, no opinion, agree, and strongly agree. 


\section{Dependent variable}

Investment Decision was measured using a proxy of 1 items on five point Likert scale (ordinal level) adopted and modified from Luu, 2014; Nyakundi (2017); Omery, 2014; Awais, Laber, Rasheed \& Khursheed 2016; Kengatharaan and Kengatharaan (2014); Garang (2016); Ojwang (2015).

\section{Independent variable}

Prospect Factors was a proxy of 5 items adopted from Dervishaj (2018); Velumoni (2017) and Herding Factorswas measured using 7 items (Lin (2011; Ghalandari \& Ghahremanpour , 2013).

\section{Data Analysis and model specification}

Analysis involved the interpretation of survey data. Once completed the study data was analyzed, that is the data collected from questionnaires using both descriptive and inferential statistics. Descriptive statistics such as frequencies, percentages, mean and standard deviation was used mainly to summarize the data. Scale reliability and validity was assessed using Cronbach's coefficient alpha and factor analysis. Further, the study employed inferential statistics in form of multiple regression and Pearson correlations analyses.

InvDec $=\beta \mathrm{O}+\beta_{1} \mathrm{X}_{1}+\varepsilon$

$\mathrm{X}_{4}=$ prospect

Where:

InvDec- Investment Decision

$\mathrm{X}_{1-\text { prospect }}$

$\beta$-is a constant

$\varepsilon$-is Error term (unexplained variation due to other unmeasured factors).

\section{Findings}

This section provides findings of the empirical research on the direct relationship between prospect bias with investment decisions among small and micro enterprises in Nairobi County. The data also was checked for reliability which assisted to ensure that all the questions were reliable. A total of 383 questionnaires were given to SMEs within Nairobi. After data collection and screen completely filled questionnaires were 375 which represent $97.9 \%$ about 5 questionnaires were 
scantly answered and could not be used in data analysis which was not include in the 375 completed questionnaires, remaining with 370 .

Descriptive statistics were obtained using mean and standard deviation. These were used for interpreting the findings and come up with conclusion about the study. The data was expressed in terms of, mean, standard deviation, skewness and kurtosis for each overconfident, anchoring factor, prospect factors, herding factors, financial literacy and investment decision. Prospect is a situation whereby a business decision is made basing on the perceived facts about a given phenomenon. Waweru et al, (2003) described prospect as some state of mind affecting an individual's decision-making processes including regret aversion, loss aversion and mental accounting. The study therefore sought to establish the effect of prospecting on investment decision making among SMEs in Nairobi County. Table 1 highlights the results. Prospect factors summed up to a mean of 4.033 , standard deviation of 0.5908 , skewness -1.167 and kurtosis 1.393 . Factor analysis was carried out on prospect factors. The criterion for communality was fulfilled by making decision is based on high returns of an investment, most business ideas are pouched from successful stories in business, business ideas comes from experienced business entrepreneurs, most business venture are tried and proven concept with the locality and market information is important for your investment. Additionally, prospect factors cumulatively explained $43.081 \%$ of the total variance. The KMO Measure is an index for comparing the magnitude of the observed correlation coefficients to the magnitude of the partial correlation coefficients. As shown in table 1, KMO was greater than .5, and Bartlett's Test was significant 
Table 1: Prospect Factors

\begin{tabular}{lcccc}
\hline $\mathrm{n}=366$ & Mean & $\begin{array}{c}\text { Std. } \\
\text { Deviation }\end{array}$ & Skewness & loadings \\
\hline $\begin{array}{l}\text { Making decision is based on high returns of an investment } \\
\text { Most business ideas are pouched from successful stories }\end{array}$ & 4.09 & 0.62 & -1.05 & 0.71 \\
in business & 4.24 & 0.74 & -1.04 & 0.74 \\
Business ideas come from experienced business & & & & \\
entrepreneurs. & 4.37 & 0.77 & -1.28 & 0.65 \\
Most business venture are tried and proven concept with & & & & \\
the locality & 4.31 & 0.82 & -1.56 & 0.66 \\
Prospect Factors & 4.03 & 0.59 & -1.17 & \\
Kaiser-Meyer-Olkin Measure of Sampling Adequacy. & 0.66 & & & \\
Bartlett's Test of Sphericity Approx. Chi-Square & 274.61 & & & \\
df & 10 & & & \\
Sig. & 0.00 & & & \\
Total Variance Explained & & & \\
Initial Eigenvalues & 2.154 & & \\
\% of Variance & 43.081 & & \\
Cumulative \% & 43.081 & & \\
Cronbach's Alpha & .717 & & \\
\hline
\end{tabular}

Extraction Method: Principal Component Analysis. Source: Research data (2020)

Investment decision is the process of making a choice from alternatives which involves capital outlay for future cash flows in long term growth of a business. This section of the analysis highlights the findings on investment decision. As shown in table 1, the findings on investment decision summed up to a mean of 3.82, standard deviation of 0.69 , skewness -0.58 and kurtosis 0.26 . Table 4.9 shows that the factor loadings for most of the investment decision items were above 0.5. Investment decision factors notably, To sum up, the first factor accounted for $18.34 \%$ of the total variance, second factor accounted for $32.44 \%$ and the third factor $45.95 \%$ of the total variance. The Kaiser-Meyer-Olkin Measure value (0.616) was above 0.5 hence acceptable. Also, the Bartlett's Test was significant. 
Table 2. Investment Decision

\begin{tabular}{|c|c|c|c|c|}
\hline$n=366$ & Mean & $\begin{array}{l}\text { Std. } \\
\text { Dev }\end{array}$ & Skewness & loadings \\
\hline $\begin{array}{l}\text { In general, the SME satisfied with the way of making } \\
\text { investment decisions }\end{array}$ & 4.24 & 0.69 & -0.96 & 0.55 \\
\hline $\begin{array}{l}\text { SME decision-making helps the enterprise to achieve its } \\
\text { investment objectives }\end{array}$ & 4.39 & 0.72 & -1.35 & 0.78 \\
\hline $\begin{array}{l}\text { SME investments decisions can mostly earn higher than } \\
\text { average return in the market }\end{array}$ & 4.21 & 0.76 & -0.82 & 0.77 \\
\hline SME make all investment decisions on its own & 4.19 & 0.77 & -0.85 & 0.59 \\
\hline $\begin{array}{l}\text { SME has increased the amount to be invested asset } \\
\text { category }\end{array}$ & 3.70 & 0.98 & -0.09 & 0.72 \\
\hline $\begin{array}{l}\text { SME has been able to open many branches in other part of } \\
\text { the country }\end{array}$ & 3.88 & 1.05 & -0.44 & 0.52 \\
\hline SME has been able to diversify its business in other sectors & 3.89 & 1.06 & -0.43 & 0.68 \\
\hline $\begin{array}{l}\text { The SME able to borrow more loans which have increased } \\
\text { its business stock }\end{array}$ & 4.11 & 0.76 & -0.72 & 0.64 \\
\hline Investment Decision & 3.82 & 0.69 & -0.58 & \\
\hline \multicolumn{5}{|l|}{ KMO and Bartlett's Test } \\
\hline Kaiser-Meyer-Olkin Measure of Sampling Adequacy. & & 0.616 & & \\
\hline Bartlett's Test of Sphericity, Approx. Chi-Square & & 283.737 & & \\
\hline Df & & 45 & & \\
\hline Sig. & & 0.000 & & \\
\hline \multicolumn{5}{|l|}{ Total Variance Explained: Rotation Sums of Squared Loadings } \\
\hline Total & 1.83 & 1.41 & & \\
\hline$\%$ of Variance & 18.34 & 14.11 & & \\
\hline Cumulative \% & 18.34 & 32.44 & & \\
\hline
\end{tabular}

Extraction Method: Principal Component Analysis.

Rotation Method: Varimax with Kaiser Normalization.

\section{Assumption of regression model}

Prior to performing inferential analyses, statistical assumptions were tested to establish if the data met the normality, linearity, heteroscedasticity, multicollinearity and autocorrelation assumptions. It was on the basis of these results, that the tests of associations and prediction were performed. The results of tests of linearity depicts that that there is a linear relationship between investment decision and prospect factors $(F=342.821, \rho$ - value $=0.000)$. Normality was checked with a goodness of fit test (that is, the Kolmogorov-Smirnov test or Shapiro-Wilk test), though this test must be conducted on the residuals themselves where that all the variables do not violate the 
normality assumption, p-value $>.05$. Heteroscedasticity was measured by Levene's test which revealed that basing on Levene statistic, homoscedasticity is not a problem for all the variables, pvalue $>.05$. This essentially means that there is a linear relationship and there is no need to have a non-linear data transformation or quadratic term to fix. VIF values higher than 10 indicate that multicollinearity is a problem. In addition, tolerance values of less than .1 indicate the presence of multicollinearity. The findings in Table 4.26 revealed that the VIF values for all the independent variables were below 10 . This means that for all the independent variables, there was no presence of multicollinearity. The Durbin-Watson test was used to test autocorrelation. Findings in showed a Durbin-Watson 2.068 which is between 1.5-2.5, indicating minimal autocorrelation which does not influence the outcome of regression results. Hence, the assumption was met.

Multivariate analysis

The study used regression and correlation analysis to test for both relationship and causal effect relationship between prospect bias and investment decisions. Table 3 found that prospect factors had significant positive relationship with investment decisions $\mathrm{R}=.698 \mathrm{Q} \leq .05$.

Hypothesis postulated that prospecting has significant effect on investment decision making among SMEs in Nairobi County. Findings showed that prospecting had coefficients of estimate which was significant basing on $\beta_{3}=0.288$ ( $\mathrm{p}$-value $=0.000$ which is less than $\alpha=0.05$ ) implying that the null hypothesis accepted and it was concluded that prospecting has a positive and significant effect on investment decision making among SMEs in Nairobi County. This indicated that for each unit increase in prospecting, there was up to 0.288 unit increase in investment decision making. The effect of prospecting was stated by the $t$-test value $=6.129$ which indicated that the effect of prospecting was 6 times that of the error associated with it. Table 1 further illustrates the model summary of multiple regression model, the results showed that all the predictors explained 68.6 percent variation of investment decision. This showed that considering the study variables of independent variables, there is a probability of predicting investment decision by $68.6 \%$ ( $\mathrm{R}$ squared $=0.686$ ). Finally, study findings in the table indicated that the above discussed coefficient of determination was significant as evidence of $F$ ratio of 86.456 with $p$ value $0.000<0.05$ (level of significance). Thus, the model was fit to predict investment decision using prospect factors. Making decision using prospect factors were based on market information, 
investment return, reputable and successful business ideas. Similar results were found by Duclos (2015) who focus investors experience and ability of utilizing information system in making decision. Incorporation of ICT that show market information of stock-distribution assisted in investment decision. Prospect theory on the other had based on Chetankumar and Hiral (2018) result had similar results that indicated significant influence of behavioural biasness on investment decision.

Table 3. Multiple Regression Results

\begin{tabular}{|c|c|c|c|c|c|}
\hline & \multicolumn{2}{|c|}{$\begin{array}{l}\text { Unstandardized } \\
\text { Coefficients }\end{array}$} & \multicolumn{3}{|c|}{ Standardized Coefficients } \\
\hline & B & Std. Error & Beta & $\mathrm{t}$ & Sig. \\
\hline (Constant) & -0.743 & 0.222 & & -3.344 & 0.001 \\
\hline Prospect Factors & 0.337 & 0.055 & 0.288 & 6.129 & 0.000 \\
\hline Firm Size & 0.198 & 0.067 & 0.100 & 2.960 & 0.003 \\
\hline Business Age & 0.035 & 0.054 & 0.037 & 0.646 & 0.519 \\
\hline Experience & -0.100 & 0.053 & -0.105 & -1.877 & 0.061 \\
\hline Education & -0.016 & 0.039 & -0.016 & -0.406 & 0.685 \\
\hline Origin of Business & 0.235 & 0.153 & 0.047 & 1.537 & 0.125 \\
\hline \multicolumn{6}{|l|}{ Model Summary } \\
\hline $\mathrm{R}$ & \multicolumn{2}{|l|}{0.828} & & & \\
\hline R Square & \multicolumn{2}{|l|}{0.686} & & & \\
\hline Adjusted R Square & \multicolumn{2}{|l|}{0.678} & & & \\
\hline Std. Error of the Estimate & \multicolumn{2}{|l|}{0.39265} & & & \\
\hline Durbin-Watson & \multicolumn{2}{|l|}{2.072} & & & \\
\hline \multicolumn{6}{|l|}{ Goodness of fit } \\
\hline \multicolumn{6}{|l|}{ ANOVAa } \\
\hline $\mathrm{F}$ & \multicolumn{2}{|l|}{86.456} & & & \\
\hline Sig. & \multicolumn{2}{|l|}{0.000} & & & \\
\hline Correlation & \multicolumn{2}{|l|}{$.698^{* *}$} & & & \\
\hline
\end{tabular}

\section{Conclusion and Recommendation}

The study has established that prospect factors positively influence investment decision among SMEs in Nairobi County. Emphasis is on loss avoidance since the entrepreneur engage in business that have been tried and proven. Also, decision making is based on high returns of an investment 
to ensure that maximum benefits are reaped from the risks taken. Prospect theory is highly linked with prospect factors where the findings showed that prospect factors had significant effect on investment decision. Despite, financial literacy not affecting the interactive effect on prospect factors. The study strongly related the theory to investment decision and showed that people frame and value a decision involving uncertainty and therefore they look at choices in terms of potential gains or losses in relation to a specific reference point, which is often the purchase price. There exists a connection between prospect factors and financial literacy which the theory explained that prospect theory explain how prospect factor relates to financial decision which is contributed by the prospect factor. This explain the insignificant interactive effect between financial literacy on prospect factors and investment decision. Therefore, entrepreneurs should consider carefully before making investment decisions though they should not care too much about the prior loss for their later investment decisions. Furthermore, decision making needs to be based on high returns of an investment. Besides, to avoid loss making, entrepreneurs should emphasize on businesses that have been tried and proven.

\section{References}

Awais, M., Laber, M. F., Rasheed, N., \& Khursheed, A. (2016). Impact of Financial Literacy and Investment Experience on Risk Tolerance and Investment Decisions: Empirical Evidence from, 6(1), 73-79.

Dervishaj, B. (2018). Psychological Biases, Main Factors of Financial Behaviour - A Literature Review. European Journal of Natural Sciences and Medicine, 1(2), 25-35.

Duclos, R. (2015). Science Direct The psychology of investment behavior: (De) biasing financial decision-making one graph at a time. Journal of Consumer Psychology, 25(2), 317-325.

Evans, J. St. B. T. (2008). Dual-processing accounts of reasoning, judgment and social cognition. Annual review of psychology, 59, 255-278

Fisher, C. (2010). Researching and writing a dissertation, an essential guide for business students (3rd ed.). Pearson Education Limited.

Fulfer, J. \& Maille, P. (2018). Power and Prospect Theory. 10.13140/RG.2.2.12322.94409.

Garang, M. (2016). The Effect of Financial Literacy on Investment Decisions in the Juba City South Sudan.

Ghalandari, K., \& Ghahremanpour, J. (2013). The Effect of Market Variables and Herding Effect on Investment Decision as Factor Influencing Investment Performance in Iran. Journal of Basic Application Research, 3(3), 313-318. 
Kahneman, D. \& Tversky A. (1979). Prospect Theory: An analysis of Decision under Risk. Econometrica, 47(2), 263-291

Kengatharan, L., Kengatharan, N., (2014). The Influence of Behavioral Factors in Making Investment Decisions and Performance: Study on Investors of Colombo Stock Exchange, Sri Lanka. Asian Journal of Finance \& Accounting 6(1), 1-23

Luu, T., (2014). Behavior Pattern of Individual Investors in Stock Market. International Journal of Business and Management, 9(1), 1-16

Nyakundi, J., (2017). Effect of behavioral biases on ranking of financing decisions by financial managers of firms listed in the Nairobi Securities Exchange. Master's thesis submitted to USIU.

Ojwang, P. (2015). Behavioral Factors and Investment Decisions. Unpublished report.

Omery, C. S (2014). The effect of behavioral factors on individual investor choices at the Nairobi Securities Exchange. Master's Thesis, University of Nairobi.

Schwab, K. (2017). The fourth industrial revolution. Currency.

Sochi, M. (2018). Behavioral Factor Influencing Investment Decision of the Retail Investors of Dhaka Stock Exchange: An Empirical Study. The Cost and Management. 46(1). 20-29.

Velumoni, D. (2017). Analysis of prospect theory on equity investment decision making - a behavioural perspective. Indian Journal of Science Research, 14(1), 211-215.

Wainaina, W. (2020). How death of supermarkets has ruined thousands of lives. Daily newspaper, $12^{\text {th }}$ January 2020.

Waweru, N. M., Munyoki, E., \&Uliana, E. (2003). The effects of behavioral factors in investment decision-making: a survey of institutional investors operating at the Nairobi Stock Exchange. International Journal of Business and Emerging Markets, 1(1), 24-41. 